NBER WORKING PAPER SERIES

\title{
BARRIERS TO ELECTRIFICATION FOR "UNDER GRID" HOUSEHOLDS IN RURAL KENYA
}

\author{
Kenneth Lee \\ Eric Brewer \\ Carson Christiano \\ Francis Meyo \\ Edward Miguel \\ Matthew Podolsky \\ Javier Rosa \\ Catherine Wolfram \\ Working Paper 20327 \\ http://www.nber.org/papers/w20327 \\ NATIONAL BUREAU OF ECONOMIC RESEARCH \\ 1050 Massachusetts Avenue \\ Cambridge, MA 02138 \\ July 2014
}

We thank Marshall Burke, Dimitri Gershenson and seminar participants at Toulouse School of Economics, "The Economics of Energy Markets," for useful comments. This research was made possible with the support and cooperation of the Rural Electrification Authority. This work was supported by the Development Impact Lab (USAID Cooperative Agreements AID-OAAA-13-00002 and AID-OAA-A-12-00011, part of the USAID Higher Education Solutions Network), the Blum Center for Developing Economies, the Berkeley Energy and Climate Institute, the UC Center for Energy and Environmental Economics, and the Center for Effective Global Action. The views expressed herein are those of the authors and do not necessarily reflect the views of the National Bureau of Economic Research.

NBER working papers are circulated for discussion and comment purposes. They have not been peer-reviewed or been subject to the review by the NBER Board of Directors that accompanies official NBER publications.

(C) 2014 by Kenneth Lee, Eric Brewer, Carson Christiano, Francis Meyo, Edward Miguel, Matthew Podolsky, Javier Rosa, and Catherine Wolfram. All rights reserved. Short sections of text, not to exceed two paragraphs, may be quoted without explicit permission provided that full credit, including $\odot$ notice, is given to the source. 
Barriers to Electrification for "Under Grid" Households in Rural Kenya

Kenneth Lee, Eric Brewer, Carson Christiano, Francis Meyo, Edward Miguel, Matthew Podolsky, Javier Rosa, and Catherine Wolfram

NBER Working Paper No. 20327

July 2014, Revised July 2016

JEL No. O18,O55,Q01,Q41

$\underline{\text { ABSTRACT }}$

In Sub-Saharan Africa, 600 million people live without electricity. Despite ambitions of governments and donors to invest in rural electrification, decisions about how to extend electricity access are being made in the absence of rigorous evidence. Using a novel dataset of 20,000 geotagged structures in rural Western Kenya, we provide descriptive evidence that electrification rates remain very low despite significant investments in grid infrastructure. This pattern holds across time and for both poor and relatively well-off households and businesses. We argue that if governments wish to leverage existing infrastructure and economies of scale, subsidies and new approaches to financing connections are necessary.

Kenneth Lee

Department of Agricultural and Resource Economics

University of California, Berkeley

Berkeley, CA 94720

kennethlee@berkeley.edu

Eric Brewer

Electrical Engineering and Computer Sciences

University of California, Berkeley

Berkeley, CA 94720

brewer@eecs.berkeley.edu

Carson Christiano

Center for Effective Global Action

University of California, Berkeley

Berkeley CA 94720

christiano@berkeley.edu

Francis Meyo

Innovations for Poverty Action

P.O. Box 72427 - 00200

Nairobi, Kenya

fmeyo@poverty-action.org
Edward Miguel

Department of Economics

University of California, Berkeley

530 Evans Hall \#3880

Berkeley, CA 94720

and NBER

emiguel@econ.berkeley.edu

Matthew Podolsky

Electrical Engineering and Computer Sciences

University of California, Berkeley

Berkeley, CA 94720

podolsky@berkeley.edu

Javier Rosa

Electrical Engineering and Computer Sciences

University of California, Berkeley

Berkeley, CA 94720

javirosa@eecs.berkeley.edu

Catherine Wolfram

Haas School of Business

University of California, Berkeley

Berkeley, CA 94720-1900

and NBER

wolfram@haas.berkeley.edu 


\section{Introduction}

In Sub-Saharan Africa nearly 600 million people-or $70 \%$ of the population-live without electricity (IEA 2013). This region contains nearly half of the unelectrified households in the world and decisions about how to increase energy access will have major implications for poverty alleviation and global climate change. Yet there is limited evidence on even the most basic patterns of energy demand and the socio-economic impacts of electrification in Africa.

Policy makers, non-governmental organizations, and donors often assume that the majority of the unelectrified are "off grid," or too far away to realistically connect to a national electricity network. The International Energy Agency constructs its World Energy Outlook forecasts using an assumption that mini-grids and small, stand-alone off-grid solutions will be required for $70 \%$ of all rural areas in developing countries (IEA 2012). As a result, there is growing support for off-grid, distributed energy approaches, most of which are best suited for regions without access to grid power. At the same time, the cost-benefit calculations driving large-scale energy infrastructure investments tend to be based on the assumption that "if you build it, they will come." In this view, expanding high voltage distribution networks and building out greater generation capabilities should translate into increased connectivity for rural households and businesses.

In this paper, we present novel descriptive evidence to address both of these assumptions using an original dataset of over 20,000 geo-tagged structures located across 150 rural communities in Western Kenya. Our study focuses on a region in which we would expect to find evidence of rapid growth in rural connectivity. Since 2007, Kenya has experienced a period of economic growth. In addition, the recent push to expand rural grid coverage nationwide has resulted in higher levels of electricity access, particularly in the densely populated counties of Western Kenya. Keeping these factors in mind, we collected rich spatial and economic data in each of our sample communities on the universe of rural structures, including households, businesses, and public facilities, to produce a unique high-resolution dataset illustrating local electrification rates in this region. We are not aware of any other comparable dataset with a similar level of detail in a low-income setting. 
Using our high-resolution data, we estimate local household and business electrification rates and identify the correlates of household connectivity. We also combine our household-level data with detailed geo-coded information on the local distribution network, in terms of transformers and connection points, to generate relevant statistics on the location or households with respect to the grid. In addition, we create a new distinction between households that are "off grid," meaning that they are too far away to connect to the national electrical grid without significant additional investments, and households that are "under grid," meaning that they are close enough to connect to a low-voltage line at a relatively low cost.

We demonstrate that even in a seemingly ideal setting, where there is high population density and extensive grid coverage, electrification rates remain very low, averaging 5\% for rural households and $22 \%$ for rural businesses. This pattern holds across time and is observed for both poor and relatively well-off households and businesses. Furthermore, we find that half of the unconnected households in our sample are "under grid," or clustered within just 200 meters of a low-voltage power line. We argue that if governments wish to leverage existing grid infrastructure, subsidies and new approaches to financing are necessary. In regions that have yet to build out grid or off-grid infrastructure, we highlight the need for forward-looking policies that consider household and business demand for connections, as well as potential economies of scale in costs.

Our work is related to the literature that estimates the impact of electrification on development outcomes. Several studies suggest that rural electrification drives improvements in employment, health, agricultural productivity, and education (see, e.g., Dinkelman 2011; Khandker et al. 2012; Kitchens and Fishback 2013; Lipscomb et al. 2013; Barron and Torero 2014). Additionally, most of the growth in energy demand over the coming decade is predicted to come from low-income countries (Wolfram et al. 2012). For these reasons, policy makers have begun to view energy poverty with an increasing sense of urgency. The challenge to electrify Africa rapidly while minimizing environmental impacts has led to the formation of high profile efforts to achieve universal energy access, including Sustainable Energy for All, a joint venture of the United Nations and the World Bank, and President Obama's Power Africa initiative. Similarly, there is increasing momentum in the private sector to finance and commercialize off-grid solutions that 
can provide rural households with enough renewable power to light a room or charge a mobile phone.

While academics and policymakers agree that modern energy is a key input to development, there are fundamental disagreements concerning how best to expand energy access in rural areas. A number of organizations promote off-grid solutions-such as solar lanterns, solar home systems, and microgrids-over the alternative of existing grid infrastructure under the presumption that these alternatives would be less environmentally damaging. ${ }^{1}$ Others remain critical of this approach. For example, The Breakthrough Institute describes it as, "a vision of, at best, charity for the world's poor, not the kind of economic development that results in longer lives, higher standards of living, and stronger and more inclusive socioeconomic institutions."2

These debates, however, take place in a data vacuum that this paper seeks to fill. We document that there are a number of households in Western Kenya that remain unconnected, even though there are electricity lines nearby. Moreover, the presumption that increasing the number of gridconnected households would lead to environmental damage may not necessarily hold in Kenya, where over $60 \%$ of current installed generation capacity (roughly 1,700 MW) comes from non fossil fuel sources such as hydro and geothermal. Furthermore, there are plans to build an additional 5,000 MW of capacity by 2017 of which more than $50 \%$ will be comprised of geothermal and wind sources. With its relatively "green grid," it may be possible for Kenya to substantially raise rural energy access without leaning too heavily on increases in fossil fuel consumption.

Our findings also relate to existing work on technology adoption that highlights the importance of social, behavioral, and other factors in influencing take-up of new technologies in Africa (see, e.g., Kremer and Miguel 2007; Duflo, Kremer and Robinson 2011; Jack and Suri 2011). However, grid electricity differs from previously studied technologies such as deworming, fertilizers and perhaps even mobile phones in that physical structures must be individually integrated into a wider network - in order to connect to power, there must be an electric line

\footnotetext{
${ }^{1}$ Examples of organizations promoting off-grid solutions include the IEA and the Sierra Club.

2 Trembath, Alex. 2014. The Low-Energy Club. The Breakthrough Institute. Available at http://thebreakthrough.org/index.php/programs/energy-and-climate/the-low-energy-club.
} 
nearby. Furthermore, the interconnected physical electrical network has important economies of scale in terms of cost. When one household connects, it becomes far cheaper for neighboring households to connect, pointing to the existence of a positive externality associated with each new connection. In standard economic theory, externalities provide a rationale for providing public subsidies to achieve socially desirable outcomes.

This paper is organized as follows. Section II provides a brief background on rural electrification in Kenya. Section III describes our data collection strategy. Section IV provides a summary of the leading patterns that emerge from our dataset. Section V discusses the implications of our results.

\section{Background}

In Kenya, rural electrification first became a public priority in 1973 with the establishment of the Rural Electrification Programme, a government plan to subsidize the cost of electricity supply in rural areas. Under this initial setup, rural electrification was the joint responsibility of the Ministry of Energy and its implementing partner, Kenya Power (KPLC), the country's regulated monopoly transmission, distribution, and retail company. ${ }^{3}$ Over the next few decades, however, the pace of rural electrification remained stagnant. The cost of grid expansion was prohibitively high and there was a general perception that demand for energy in rural areas was too low to be financially viable.

In recent years, there has been a dramatic increase in the coverage of the national electricity grid. In 2003, a mere 285 public secondary schools across the country were connected to electricity. By November 2012, Kenyan newspapers were projecting that $100 \%$ of the country's 8,436 secondary schools would soon be connected. This recent big push to electrify rural Kenya began with the ratification of the Energy Act of 2006, which restructured the country's electricity sector and created the Rural Electrification Authority (REA), an agency that would operate independently of Kenya Power, and would be in charge of accelerating the pace of rural

\footnotetext{
${ }^{3}$ Initially, KPLC was also the largest power-producing company in Kenya. The Kenya Electricity Generating Company (KenGen), the country's main power producer, was established in 1998 in a spin-off of KPLC.
} 
electrification. Almost immediately, REA announced a strategy to prioritize the connection of three major types of rural public facilities - markets, secondary schools and health clinics. In the densely populated regions of Central and Western Kenya, where the majority of the population lives, it is widely believed that households are within walking distance of multiple public facilities, although detailed data verifying these claims are lacking. By following this strategy, public facilities would not only benefit from electricity but could also serve as community connection points, bringing previously off-grid homes and businesses within reach of the grid.

By 2013, REA announced that $90 \%$ of the country's public facilities had been electrified suggesting that a large share of the population had access to the electricity grid. Despite this success, estimates of the national household electrification rate remain just between 18 and $26 \%$. This gap-between those who are believed to live within range of power and those who are connected to power-suggests that "last-mile" grid connections could be important moving forward.

\section{Data collection strategy}

Estimates of grid coverage and grid connectivity in developing countries suffer from uncertainty and measurement error. There is a need for better data on the extent to which unelectrified rural households and businesses are truly "off grid," and the barriers to last-mile electrification where grid infrastructure is already present. We examine these questions by first defining a basic spatial unit-what we refer to as a "transformer community" - to include all buildings within 600 meters of a transformer (the distance at which the utilities deem a building eligible to apply for a grid connection). Our analysis focuses on 150 transformer communities that had transformers installed by REA between 2008 and 2013. All of these communities are located in Busia and Siaya, two Western counties that are broadly representative of rural Kenya in terms of electrification rates and socio-economic development. Given the high population density in this region, the potential for rapid rural electrification is high. After defining our transformer communities, we conducted a census of all households, businesses and public facilities to

\footnotetext{
${ }^{4}$ The 18\% figure comes from The World Bank Databank (available at: http://data.worldbank.org/); the 26\% figure comes from REA (available at: http://www.rea.co.ke/index.php?option=com_docman\&task=cat_view\&gid=4\&Itemid $=505)$.
} 
determine electrification status and collect data on observable attributes of each building.

\section{Community selection}

In August 2013 local representatives of REA provided us with a master list of 241 unique REA projects, consisting of roughly 370 individual transformers spread across the ten constituencies of Busia and Siaya. Each project featured the electrification of a major public facility (market, secondary school, or health clinic), and involved a different combination of high and low voltage lines and transformers. Projects that were either too recent, or not commissioned, were not included in this master list. ${ }^{5}$

In September 2013 we randomly selected 150 transformers using the following procedure: 1) in each constituency, individual transformers were listed in a random order, 2) the transformer with the highest ranking in each constituency was then selected into the study, and 3) any remaining transformers located less than $1.6 \mathrm{~km}$ (or 1 mile) from, or belonging to the same REA project as one of the selected transformers, were then dropped from the remaining list. We repeated this procedure, cycling through all ten constituencies, until we were left with a sample of 150 transformers for which: 1) the distance between any two transformers was at least $1.6 \mathrm{~km}$, and 2) each transformer represented a unique REA project. In our final sample, there are 85 and 65 transformers in Busia and Siaya counties, respectively, with the number of transformers in each of the ten constituencies ranging from 8 to $23 .^{6}$

\section{Sample representativeness}

Table 1 presents a basic comparison between the sample counties, and all other counties in Kenya, excluding Nairobi and Mombasa, which are entirely urban. In general, counties in Western Kenya tend to have higher population densities with a higher share of rural homes. For example, the population per square kilometer in the sample region is 375.4 compared to the nationwide county-level median of 183.2. The population density of the 150 transformer

\footnotetext{
${ }^{5}$ Since the primary objective was to estimate local electrification rates, projects that were funded after February 2013 were excluded to ensure that each community had reached a stable point in terms of electricity take-up.

${ }^{6}$ This variation can be attributed to differences across constituencies in land size and population density. In smaller constituencies, or constituencies where transformers were bundled closely together, our list of potential sites was exhausted before the selection process was complete.
} 
communities in our sample, however, is lower, averaging 238.1 people per square kilometer.

Although population and household density are relatively high, Busia and Siaya are broadly representative of — or lag just behind — other parts of rural Kenya in terms of basic education and income indicators. For example, the proportion of people with a secondary school education is $10.4 \%$ in our sample region, just below the nationwide county-level median, and the proportion of buildings with high quality walls (i.e. those made of brick, cement, or stone) is $32.5 \%$, just above the nationwide county-level median. With respect to the number of public facilities (i.e. secondary schools, markets, and health clinics), the sample region has 0.81 public facilities per 1,000 people, which is slightly above the nationwide county-level median of 0.75 . Even though the sample region is highly populated, there is a similar density of public facilities compared to the rest of Kenya.

Based on the 2009 Kenya Population and Housing Census, rural and urban electrification rates in Busia and Siaya are low compared to other parts of Kenya, perhaps because these are relatively rural counties. A more appropriate question would address whether our sample is representative in terms of grid penetration. Would the "under grid" observation apply to other parts of the country? By July 2013, REA had identified 26,070 rural public facilities, located across the 46 non-Nairobi counties in Kenya, of which 22,860 were deemed to be electrified. This implied a national public facility electrification rate of $87.7 \%$ and a median county-level rate of $88.2 \%$. In comparison, public facility connectivity in our sample region was 84.1\%. Levels of grid penetration in Busia and Siaya are therefore similar to those found in other parts of the country.

\section{Data collection}

Between September and December 2013, teams of Innovations for Poverty Action (IPA) surveyors visited each of the 150 transformer communities to geotag each structure within 600 meters of the central transformer and to determine whether the structure had a visible electricity connection at the time of the visit. We identified households at the level of the residential compound, which is a unit known locally as a boma. In Western Kenya, it is common for related families to live in different households but share the same compound. In our sample of 13,107 compounds, $29 \%$ consist of multiple households. Throughout this paper, we refer to these 
compounds as households. In each community, we were assisted by local guides to quickly capture basic socio-economic indicators for each structure, such as building quality, household size, and whether there was a known business operating inside the household.

\section{Data visualization}

We create a series of maps, presented in Figure 1 (and Figures A1 to A3 in the Appendix), to illustrate the degree to which rural Kenyans are living close to existing national grid infrastructure. In these maps, the white circle labeled " $\mathrm{T}$ " in the center identifies the location of the REA transformer. The larger white outline demarcates the 600-meter radius boundary. Green circles represent unconnected households; purple squares represent unconnected businesses; and blue triangles represent unconnected public facilities. Yellow circles, squares, and triangles indicate households, businesses, and public facilities with visible electricity connections, respectively. Household markers are scaled by household size, with the largest indicating households with more than ten members, and the smallest indicating households with single members.

Our maps depict several patterns. For example, businesses and public facilities (squares and triangles) appear to be located along the roads, while households (circles) tend to be scattered across the countryside. Also, across the communities depicted in Figures 1 (and Figures A1 to A3), it is readily apparent that a large proportion of unconnected households (green circles) are located near existing connection points (yellow circles, squares, and triangles).

\section{Findings}

In this section, we discuss three leading patterns that emerge from our data.

\section{Despite large investments in grid infrastructure, electrification rates remain low even up to} five years after infrastructure has been built.

Extending the grid across rural Kenya has been costly. A typical REA project involves the construction of 11,000 V (11 kV) high-voltage lines, secondary distribution transformers, single 
and three-phase low-voltage lines, and drop-down lines for last-mile connections. Since these projects are implemented in remote areas, additional costs associated with transportation, surveying and design, and temporary shutdowns tend to be high. In our sample, the median cost of a single REA project is KSh 2.5 million, or $\$ 29,548 .^{7}$ If we divide the cost of each REA project by the number of transformers in the project, the estimated median cost of each deployed transformer in our sample is $\$ 21,820 .^{8}$

This high cost could potentially be justified if many of the surrounding households and businesses were connected to the grid. ${ }^{9}$ The majority of households in our sample region are willing to pay for an electricity connection. Based on a random sub-sample of 265 unconnected households, 55\% state that they would connect if the prices were just $30 \%$ lower. Nonetheless, local electrification rates remain low, averaging $5.5 \%$ and $22.3 \%$ for households and businesses in our sample of transformer communities, respectively. ${ }^{10}$ By dividing the estimated cost of each transformer by the total number of observed connections-including households, businesses and public facilities-we highlight the degree to which this infrastructure is currently underutilized. In our sample, the median infrastructure investment per connection is $\$ 2,427$. Yet if every structure within each transformer community were to connect, this figure would drop to $\$ 210$.

It is possible that electrification rates are low because the communities we analyze were electrified only recently; connectivity may naturally increase over time. In order to assess whether electrification rates remain low over time, we categorize our sample of transformers by REA project year and compare electrification rates. The REA project year is the fiscal year in which each project was nominated for electrification by the local Constituency Development Fund and funded in the REA system. Typically, transformers are commissioned within several

\footnotetext{
${ }^{7}$ For all currency conversions, we assume an exchange rate of $85 \mathrm{KSh}$ per U.S. dollar.

${ }^{8}$ These estimates are based on actual cost data supplied by REA. We were provided with budgetary estimates for 127 projects and actual expenditures for 121 projects in our sample. Most of the projects with missing data were funded in 2008-09 and the data were not recorded in the latest database.

${ }^{9}$ In our sample, there are an average of 85 households and 19 businesses in each transformer community.

${ }^{10}$ We estimate local electrification rates by dividing the total number of structures with a visible electricity connection by the total number of structures observed within the boundaries of the transformer community. Household electrification refers to connectivity at the compound level.
} 
months of being funded. ${ }^{11}$

In Figure 2, we plot average rates for communities grouped by year, with the most recently connected group appearing on the left. The figure illustrates that electrification rates have steadily increased over time for both households and businesses but remain at relatively low levels, even after five years. Even for the oldest transformers in our sample, those funded during 2008-09, the average household electrification rate is $8.9 \%$. Selection issues, however, may confound our interpretation of these results. Communities with higher take-up potential may have been electrified first, resulting in upward sloping curves. Yet even if we acknowledge this selection issue, electrification rates remain low.

In our sample of 2,824 businesses, $33.6 \%$ are visibly connected to power. In Table 2, we report the average electrification rate and number of observations for the ten most commonly observed types of rural businesses. There is considerable variation across types. Connectivity is the lowest for small food stands at $5.7 \%$ and the highest for barbershops and salons at $63.2 \%$. These differences form a snapshot of the demand for business electrification in rural areas. Barbershops and hair salons cannot operate effectively without power, and given the relatively low cost of related electrical appliances, connectivity is quite high. Surprisingly, connectivity is low for the more energy-intensive business types. Only $13.3 \%$ of cornmeal "posho" mills— the business type that is found across the largest number of communities-are visibly connected, suggesting that the majority of millers are still operating diesel motors. Similarly, connectivity for welding, carpentry and workshops is relatively low at $39.2 \%$.

\section{Connectivity is low even for relatively well-off rural households and businesses.}

Should low levels of connectivity be attributed to a technical or an economic constraint? On the one hand, since it is technically easier to supply a connection to a building that is close to a transformer, connectivity should be lower for households that are further away from a transformer. On the other hand, the current connection price of KSh 35,000, or $\$ 412$, may not be

\footnotetext{
${ }^{11}$ There is no reliable data on precise transformer commissioning dates in Western Kenya.
} 
affordable for poor, rural households in a country where the GNI per capita (PPP) is $\$ 1,730 .^{12}$ Connectivity should be lower for households with visible markers of poverty, such as lowquality building materials.

In our dataset of over 13,000 households, 76.4\% have low-quality walls, made of mud, reeds, wood, or iron, and $23.6 \%$ have high-quality walls, made of brick, cement, or stone. For each structure, we use the GPS coordinates to calculate straight-line distances to the central transformer, as well as the nearest distance to any type of connected structure to approximate distances to low-voltage lines. In Figure 3, we plot locally weighted regressions of connection status on distance to the central transformer for businesses and households with high and lowquality walls. While the likelihood of being connected improves slightly with proximity to the transformer, there is a much larger improvement when households have better walls.

In Table 3, we report ordinary least squares regression results using connection status as the outcome variable, and distance, wall quality and their interaction as the explanatory variables. These coefficients are estimated using the regression model

$$
y_{i c}=\beta_{1} d_{i c}+\beta_{2} w_{i c}+\beta_{3} d_{i c} \times w_{i c}+\lambda_{c}+\varepsilon_{i c}
$$

where $y_{i c}$ is an indicator variable for whether or not structure $i$ in community $c$ was visibly connected to electricity, $d$ is the straight line distance between the structure and the central transformer (in 100 meter units), $w$ is an indicator variable for whether or not the structure had high-quality walls (e.g. brick, cement, or stone), and $\lambda_{c}$ captures community fixed effects to account for site-level differences in market status or geography. The coefficients in column 2 suggest that a household with high-quality walls is $3 \%$ more likely to be connected if it is 20 meters away than if it is 200 meters away. In comparison, at 200 meters, a household with highquality walls is $22 \%$ more likely to be connected compared to a household with low-quality walls.

\footnotetext{
${ }^{12}$ In March 2014, Kenya Power, the national utility, stated that it will continue to charge eligible customers $\$ 412$ for single-phase power connections, as long as the cost of connection does not exceed $\$ 1,588$, inclusive of VAT.
} 
Nonetheless, connectivity is under $30 \%$ for these relatively well-off households, most likely because the majority of these households are still poor. While high-quality walls correlate with being better off, the difference in primary economic activity between households with high and low-quality walls in our sample is not large. Based on a sub-sample of 1,737 households in our transformer communities, $70 \%$ of households with high-quality walls list small-scale farming as a primary economic activity, compared to $77 \%$ of households with low-quality walls. Taken together, the above patterns suggest that the current connection price is simply too high for rural households and businesses. In ongoing work, we are experimentally varying the connection cost to assess this hypothesis directly.

3. Half of the unconnected households in our sample are "under grid," or clustered within 200 meters of a low-voltage line, and could be connected at a relatively low-cost.

Taking advantage of the spatial nature of our data, we calculate the shortest distance between unconnected households and the nearest connection point or transformer to approximate the extent to which each household is "under grid." These estimates are conservative. Since our data are limited to the 600-meter circles drawn around each transformer, these are upper bounds on the actual distance because there may be other low-voltage lines immediately beyond our mapped boundaries. In Figure 4, we plot the density of the 12,001 unconnected households and 1,875 unconnected businesses in our data set using this metric along the horizontal axis.

Although every structure within a transformer community is eligible to apply for a connection, this is not enough to guarantee that an application will be immediately fulfilled by the local utilities. From the supplier's perspective, it is preferable to connect buildings that are no more than a few service poles away from a low-voltage line because the installation costs associated with single, distant connections are much higher. ${ }^{13}$

According to REA, service poles are required for every 50 meters of line; three or four service poles would therefore imply a maximum distance of 150 to 200 meters. We conservatively estimate the incremental cost of supplying an electricity connection to a single household 200

\footnotetext{
${ }^{13}$ This is based on multiple discussions with REA and Kenya Power representatives that took place between July 2013 and March 2014.
} 
and 100 meters away from a low-voltage line to be $\$ 1,940$ and $\$ 1,058$, respectively, inclusive of material and transportation costs, as well as a $25 \%$ contractor markup. ${ }^{14}$ Once connected, households pay the utility an electricity tariff that is structured to cover the cost of additional power generation.

These cost estimates, however, do not account for the significant economies of scale that could be achieved by connecting multiple households along the same length of line at the same time. In Figure 5, we plot estimates of the cost economies of scale based on the number of connections and the distance to a low voltage line. For example, if two neighboring households were to connect, the above per household costs would fall by roughly $47 \%$, to $\$ 1,021$ and $\$ 580$ for distances of 200 and 100 meters, respectively. These households could be located as far as 30 meters away from either side of the line. The average cost does not decrease by $50 \%$ because each household would still require its own service line. If six households were to connect, these estimates would drop to $\$ 409$ and $\$ 262$, respectively. While we do not have adequate data to estimate marginal costs in a mass connection program, the costs would presumably be much lower. For instance, if we ignore transportation costs and assume that there is no need to build any additional distribution lines, the marginal cost of a single connection would theoretically fall to $\$ 80$, the cost of a single-service line. Our cost estimates, presented in Figure 5, are in line with previous work on the costs of rural electrification in Kenya (see, e.g., Parshall et al. 2009).

There are no precise estimates of the overall value of electricity to a household. However, if we assume that a connection generates benefits well into the future and apply an annualized interest rate of $12 \%$, then an $\$ 80$ cost of connection need only generate the equivalent of $\$ 10$ per household per year in monetary and non-monetary benefits-or $0.6 \%$ of the GNI per capita-to be welfare improving. ${ }^{15}$ For instance, these benefits could come in the form of higher net profits

\footnotetext{
${ }^{14}$ This excludes additional last-mile costs of household wiring and the meter deposit that households pay to the utility. We conservatively estimate the physical cost of supplying last-mile connection costs, as well as potential economies of scale, using the following assumptions provided by REA: (a) low-voltage single-phase two-wire overhead lines costing $\$ 7.06$ per meter; (b) single-phase service lines costing $\$ 81.92$ per connection; (c) transportation costing $\$ 1.18$ per kilometer for a single lorry traveling over an average distance of $50 \mathrm{~km}$; and (d) contractor costs equal to $25 \%$ of all material and transportation costs. Since each truck can carry a maximum of 30 poles, a single vehicle would be sufficient to transport the materials for small groups of neighboring households 600 meters away from a transformer.

${ }^{15}$ The Kenya Government Bond 10 year rate was $11.44 \%$ in March 2014.
} 
for household businesses or improved educational outcomes for children. Applying a 200-meter threshold, we find that $47.2 \%$ of the 12,386 unconnected households in our sample could be deemed "under grid." These households are clustered together and are, on average, 115 meters away from a connection point. Based on our data, this represents 36,800 individuals who lack modern energy yet live within range of connecting to the grid at a relatively low cost.

\section{Conclusion}

We demonstrate that even in a seemingly ideal setting, where there is high population density and extensive grid coverage, electrification rates for rural households and businesses remain very low. This pattern holds across time and is observed for both poor and relatively well-off households and businesses. Clearly, under the status quo pricing policies, significant investments in grid infrastructure in Western Kenya have not translated into equally high rates of rural electrification. Our data does however highlight an opportunity that may inform future policies. Half of the unconnected households in our sample are "under grid," or clustered within 200 meters of a low-voltage line, and could potentially be connected at relatively low marginal cost. If this pattern were to hold across transformer communities nationwide, then given that over $90 \%$ of Kenya's major public facilities (i.e. markets, secondary schools and health clinics) are now electrified, and that these structures are spatially distributed across the country, there is a potential opportunity for millions of new connections. ${ }^{16}$

There are at least three ways in which our results could be useful in designing future electrification strategies. First, governments may wish to subsidize mass connection programs. There may be a natural redistributive motive behind this strategy. The fact that connectivity remains so low in "under grid" Kenyan communities indicates that a \$412 connection price is too high for poor, rural households to face alone. Furthermore, each new connection expands the geographic reach of the electricity network bringing more and more structures "under grid." In theory, subsidies can be useful in the presence of these types of externalities. Second,

\footnotetext{
${ }^{16}$ For example, based on REA's estimates of 8.8 million households and 26\% household electrification (http://www.rea.co.ke/index.php?option=com_docman\&task=cat_view\&gid=4\&Itemid=505), then the $50 \%$ "under grid" result would point to an opportunity for 3.3 million new connections
} 
governments may wish to support innovative financing and payment approaches to raising connectivity. The lack of a vibrant credit sector serving poor, rural households in developing countries is well documented (see, e.g., Karlan et al. 2013). Providing access to credit or financing options could help rural households meet the up-front cost associated with electrification. Third, governments may wish to support group-based subsidies that are tied to the number of applicants. When take-up is higher, it is cheaper for utilities to connect households because transportation costs are lower and it is possible to design lower-cost local distribution networks. This strategy would therefore take advantage of existing infrastructure and economies of scale. Coordinating household connections, however, poses a collective action problem that would need to be solved through government policies such as mass connection programs.

The idea of subsidizing last-mile electricity connections to households is, of course, nothing new. Between 1935 and 1939 the United States implemented its own rural electrification program, issuing roughly $0.3 \%$ of GDP_or $\$ 16$ billion in chained 2009 dollars-in government subsidized loans for rural electrification. Within two decades the proportion of electrified farms in the U.S. increased from $10 \%$ to over $90 \%$ (Kitchens and Fishback 2013). Similarly, the Tennessee Valley Authority Program, which featured major public investments in a series of hydroelectric dams, has been attributed to persistent growth in regional manufacturing (Kline and Moretti 2013).

Our results highlight an opportunity to greatly reduce energy poverty in Sub-Saharan Africa by targeting last-mile connections in "under grid" communities. In regions that have yet to build out grid or off-grid infrastructure, we highlight the need for forward-looking policies that take into account household and business demand for connectivity, as well as potential economies of scale in costs. In Sub-Saharan Africa, there has been a growing focus on expanding renewable generation capacity. In countries like Kenya, where there is a relatively "green grid," the usual tradeoff between energy access and environmental damage is not as salient. As governments and donors embark on the ambitious task of electrifying hundreds of millions of African households over the coming years, the novel results in this paper call for further research on the demand for and impacts of electrification as well as the potential of various financing mechanisms. 


\section{References}

Barron, Manuel, and Maximo Torero. 2014. Short Term Effects of Household Electrification: Experimental Evidence from Northern El Salvador.

Dinkelman, Taryn. 2011. The Effects of Rural Electrification on Employment: New Evidence from South Africa. American Economic Review 101, no. 7:3078-3108.

Duflo, Esther, Michael Kremer, and Jonathan Robinson. 2011. Nudging Farmers to Use Fertilizer: Theory and Experimental Evidence from Kenya. American Economic Review 101, no. 6:2350-2390.

IEA (International Energy Agency). 2013. World Energy Outlook. http://www.worldenergyoutlook.org/publications/weo-2013/.

International Energy Agency (IEA). 2012. World Energy Outlook. http://www.worldenergyoutlook.org/publications/weo-2012/.

Jack, William, and Tavneet Suri. 2011. Mobile Money: The Economics of M-PESA. NBER Working Paper 16721, National Bureau of Economic Research, Cambridge, MA. http://www.nber.org/papers/w16721.

Karlan, Dean, Robert Darko Osei, Isaac Osei-Akoto, and Christopher Udry. 2013. Agricultural Decisions after Relaxing Credit and Risk Constraints. Quarterly Journal of Economics (forthcoming).

Khandker, Shahidur, Hussain A. Samad, Rubaba Ali, and Douglas F. Barnes. 2012. Who benefits most from rural electrification? Evidence in India. Policy Research Working Paper 6095, World Bank. http://elibrary.worldbank.org/doi/pdf/10.1596/1813-9450-6095.

Kitchens, Carl, and Price Fishback. 2013. Flip the Switch: The Spatial Impact of the Rural Electrification Administration 1935-1940. NBER Working Paper 19743, National Bureau of Economic Research, Cambridge, MA. http://www.nber.org/papers/w19743.

Kline, Patrick, and Enrico Moretti. 2013. Local Economic Development, Agglomeration Economies, and the Big Push: 100 Years of Evidence from the Tennessee Valley Authority. NBER Working Paper 19293, National Bureau of Economic Research, Cambridge, MA. http://www.nber.org/papers/w19293. 
Kremer, Michael, and Edward Miguel. 2007. The Illusion of Sustainability. Quarterly Journal of Economics 122, no. 3:1007-1065.

Lipscomb, Molly, Ahmed Mobarak Mushfiq, and Tania Barham. 2013. Development Effects of Electrification: Evidence from the Topographic Placement of Hydropower Plants in Brazil. American Economic Journal: Applied Economics, 5, vol. 2:200-231.

Parshall, Lily, Dana Pillai, Shashank Mohan, Aly Sanoh, and Vijay Modi. 2009. National electricity planning in settings with low pre-existing grid coverage: Development of a spatial model and case study of Kenya. Energy Policy 37:2395-2410.

Wolfram, Catherine, Orie Shelef, and Paul Gertler. 2012. How Will Energy Demand Develop in the Developing World? Journal of Economic Perspectives 26, vol. 1:119-138. 
Table 1. Comparison of socio-economic indicators between sample region and nationwide counties.

\begin{tabular}{lcccc}
\hline \hline & & \multicolumn{2}{c}{ Nationwide county percentiles } \\
\cline { 3 - 5 } & Sample region & 25 th & 50 th & 75 th \\
\hline Total population & $1,586,250$ & 528,054 & 724,186 & 958,791 \\
per square kilometer & 375.4 & 39.5 & 183.2 & 332.9 \\
\% rural & 85.7 & 71.6 & 79.5 & 84.4 \\
\% at school & 44.7 & 37.0 & 42.4 & 45.2 \\
\% in school with secondary education & 10.3 & 9.7 & 11.0 & 13.4 \\
Total households & 353,259 & 103,114 & 154,073 & 202,291 \\
per square kilometer & 83.6 & 7.9 & 44.3 & 78.7 \\
\% with high quality roof & 59.7 & 49.2 & 78.5 & 88.2 \\
\% with high quality floor & 27.7 & 20.6 & 29.7 & 40.0 \\
\% with high quality walls & 32.2 & 20.3 & 28.0 & 41.7 \\
\% with piped water & 6.3 & 6.9 & 14.2 & 30.6 \\
Total public facilities & 1,288 & 356 & 521 & 813 \\
per capita (000s) & 0.81 & 0.59 & 0.75 & 0.98 \\
Electrification rates & & & & 92.6 \\
Rural (\%) & 2.3 & 1.5 & 3.1 & 5.3 \\
Urban (\%) & 21.8 & 20.2 & 27.2 & 43.2 \\
Public facilities (\%) & 84.1 & 79.9 & 88.1 & 92.6 \\
\hline \hline
\end{tabular}

Note: Sample region column presents aggregate and weighted-average statistics (where applicable) for Busia and Siaya counties. Demographic and socio-economic data obtained from 2009 Kenya Population and Housing Census. Public facility electrification data obtained from the Rural Electrification Authority (REA). Rural and urban electrification rates represent the proportion of households who stated that electricity was their main source of lighting during the 2009 census. National county percentiles exclude the urban counties of Nairobi and Mombasa. 
Table 2. Electrification rates for businesses of various types.

\begin{tabular}{lcc} 
& $\%$ & $\mathrm{~N}$ \\
& $(1)$ & $(2)$ \\
\hline All businesses & 33.6 & 2,824 \\
\hline Small retail & 36.2 & 1,163 \\
Posho mill & 13.3 & 294 \\
Barber shop / salon & 63.2 & 209 \\
Restaurant & 31.3 & 182 \\
Tailor & 26.5 & 162 \\
Guesthouse & 14.2 & 155 \\
Food stand & 5.7 & 140 \\
Bar / cinema / television hall & 62.9 & 105 \\
Butcher & 29.7 & 91 \\
Welding / carpentry / workshop & 39.2 & 74 \\
Other & 42.2 & 249 \\
\hline
\end{tabular}

Note: Column (1) reports the average electrification rate; (2) reports the total number of observations. 
Table 3. Predictors of electrification.

\begin{tabular}{|c|c|c|c|c|c|c|}
\hline & \multicolumn{3}{|c|}{ Households } & \multicolumn{3}{|c|}{ Businesses } \\
\hline & (1) & $(2)$ & (3) & $(4)$ & (5) & (6) \\
\hline Distance & $-0.69^{* * *}(0.14)$ & $-0.14(0.15)$ & $-0.19(0.16)$ & $-2.71^{* * *}(0.55)$ & $-2.11^{* *}(0.89)$ & $-1.39(1.06)$ \\
\hline Walls & & $25.33^{* * *}(1.26)$ & $24.98^{* * *}(1.26)$ & & $29.19^{* * *}(2.83)$ & $27.69^{* * *}(3.03)$ \\
\hline Walls*Distance & & $-1.57^{* * *}(0.31)$ & $-1.54^{* * *}(0.31)$ & & $0.79(1.11)$ & $0.08(1.21)$ \\
\hline Fixed effects & No & No & Yes & No & No & Yes \\
\hline Mean of dep. var. & 5.47 & 5.47 & 5.47 & 33.58 & 33.58 & 33.58 \\
\hline R-squared & 0.00 & 0.13 & 0.16 & 0.01 & 0.09 & 0.20 \\
\hline
\end{tabular}

Note: All columns report OLS regressions. The dependent variable is an indicator variable for household connection status. Columns (1) to (3) report results for households; Columns (4) to (6) report results for businesses. Definitions: (a) Distance is the straight line distance to the central transformer (in 100 meter units); (b) Walls is equal to 1 for buildings with high-quality walls (e.g. brick, cement, or stone) and is equal to 0 otherwise; (c) Walls*Distance is the interaction between Distance and Walls. All coefficients are multiplied by 100 . Columns (3) and (6) report community fixed effects regressions. Asterisks indicate coefficient significance level (2-tailed): ${ }^{*} \mathrm{P}<0.10$; ** $\mathrm{P}<0.05$; ** $\mathrm{P}<0.01$. 
Figure 1: Visualizing the proportion of households and businesses that are "under grid."
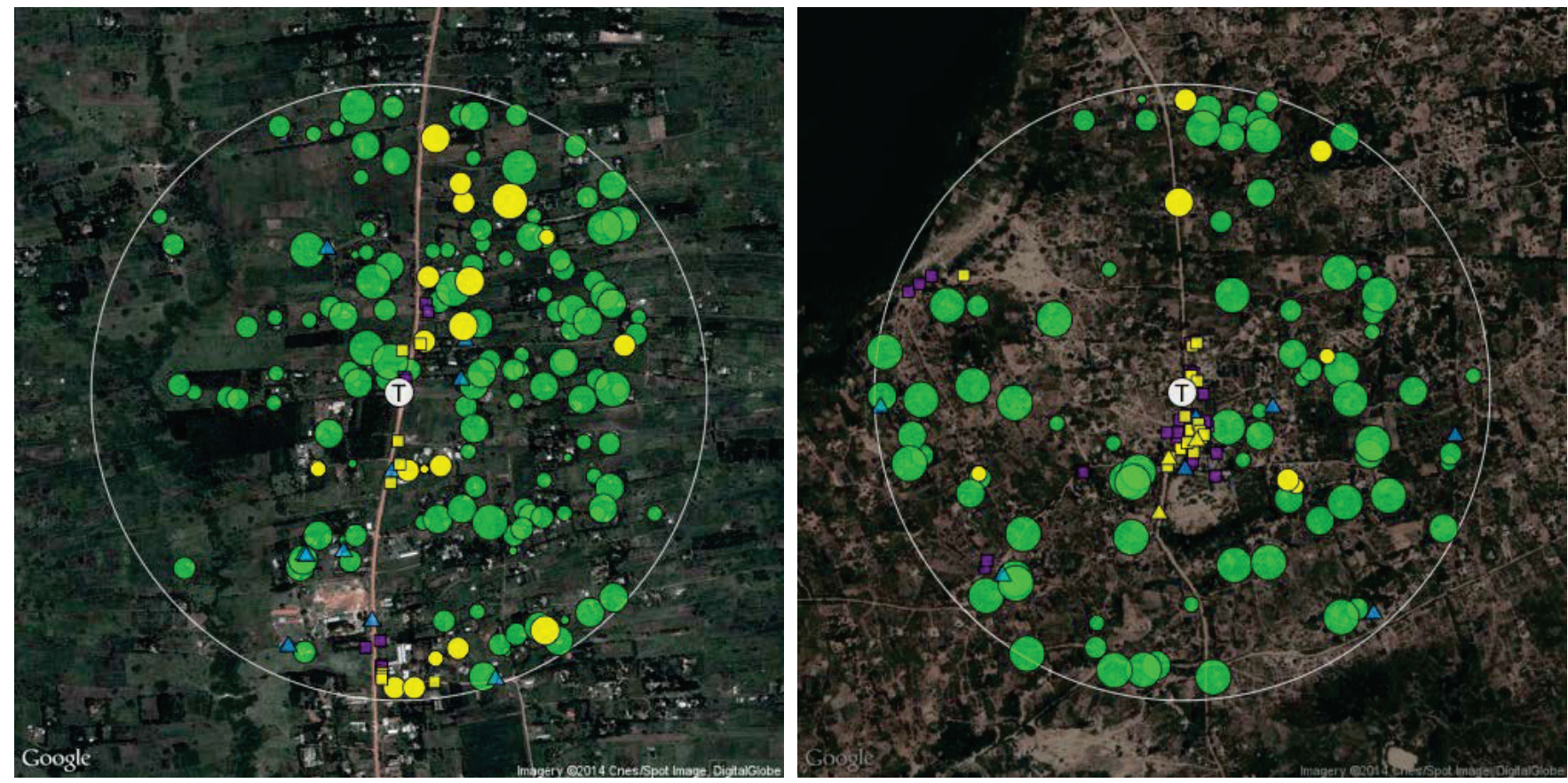

Note: In these maps, the white circle labeled "T" in the center identifies the location of the REA transformer. The larger white outline demarcates the 600-meter radius boundary. Green circles represent unconnected households; purple squares represent unconnected businesses; and blue triangles represent unconnected public facilities. Yellow circles, squares, and triangles indicate households, businesses, and public facilities with visible electricity connections, respectively. Household markers are scaled by household size, with the largest indicating households with more than ten members, and the smallest indicating single-member households. Residential rental units are categorized as households. The figures illustrate the large proportion of unconnected households (green circles) that are located near existing connection points (yellow circles, squares, and triangles). (Left) The transformer was funded/installed in 2008-09 at a secondary school (although the school itself is unconnected). Connectivity is 14\% for households and $53 \%$ for businesses, and $84 \%$ of all unconnected households in this community are "under grid," or within 200 meters of a connection point. (Right) The transformer was funded/installed in 2012-13 and located in a market center. The dark region in the upper left of the figure is Lake Victoria. Connectivity is $8 \%$ for households and $45 \%$ for businesses, and 75\% of all unconnected households are "under grid." Maps of 18 additional transformer communities are presented in Figures A1 to A3 in the Appendix. 
Figure 2: Median transformer community electrification rates by structure type and funding/installation year.

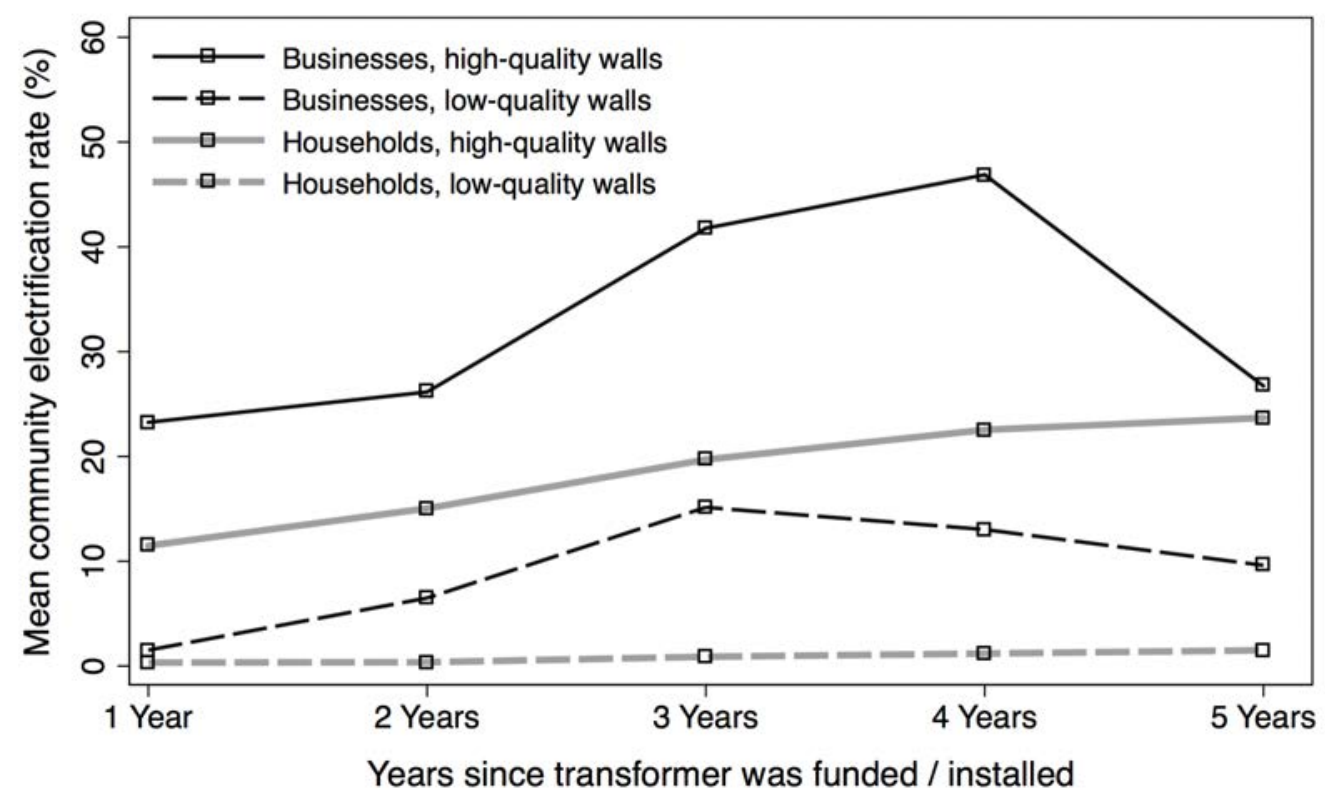

Note: Transformer communities are grouped by REA project year. The REA project year is the fiscal year in which each project was nominated and funded for electrification. There are 12, 37, 22, 58, and 21 projects in the 1 Year (2012-13), 2 Years (2011-12), 3 Years (2010-11), 4 Years (2009-10), and 5 Years (2008-09) groups, respectively. Structures with high-quality walls are defined as those made of brick, cement, or stone. Structures with low-quality walls are defined as those made of mud, reeds, wood, or iron. The figure illustrates that electrification rates have steadily increased over time for both households and businesses but remain at relatively low levels, even after five years. 
Figure 3: Connection rates by distance to the central transformer.

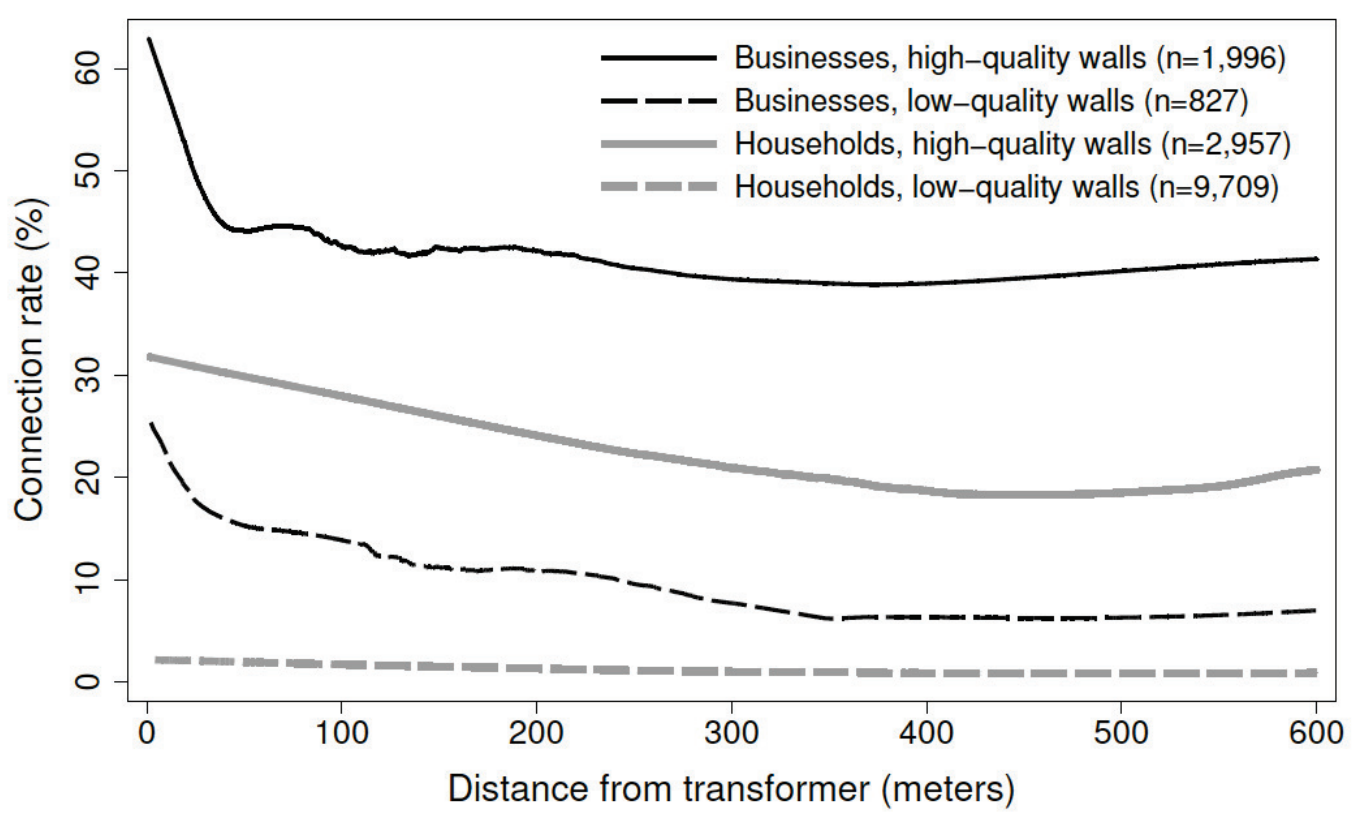

Note: In this figure, we plot locally weighted regressions (bandwidth 5) of the connection status on the distance to the transformer for businesses and households with high and lowquality walls. As in Fig. 2, high-quality walls are defined as those made of brick, cement, or stone. Low-quality walls are defined as those made of mud, reeds, wood, or iron. The figure illustrates that: (1) electrification rates are correlated with both distance from transformer, and quality of walls, for both businesses and households, and (2) even for the relatively welloff households, connectivity remains low. 
Figure 4: Kernel densities of unconnected households and businesses by distance from lowvoltage line.

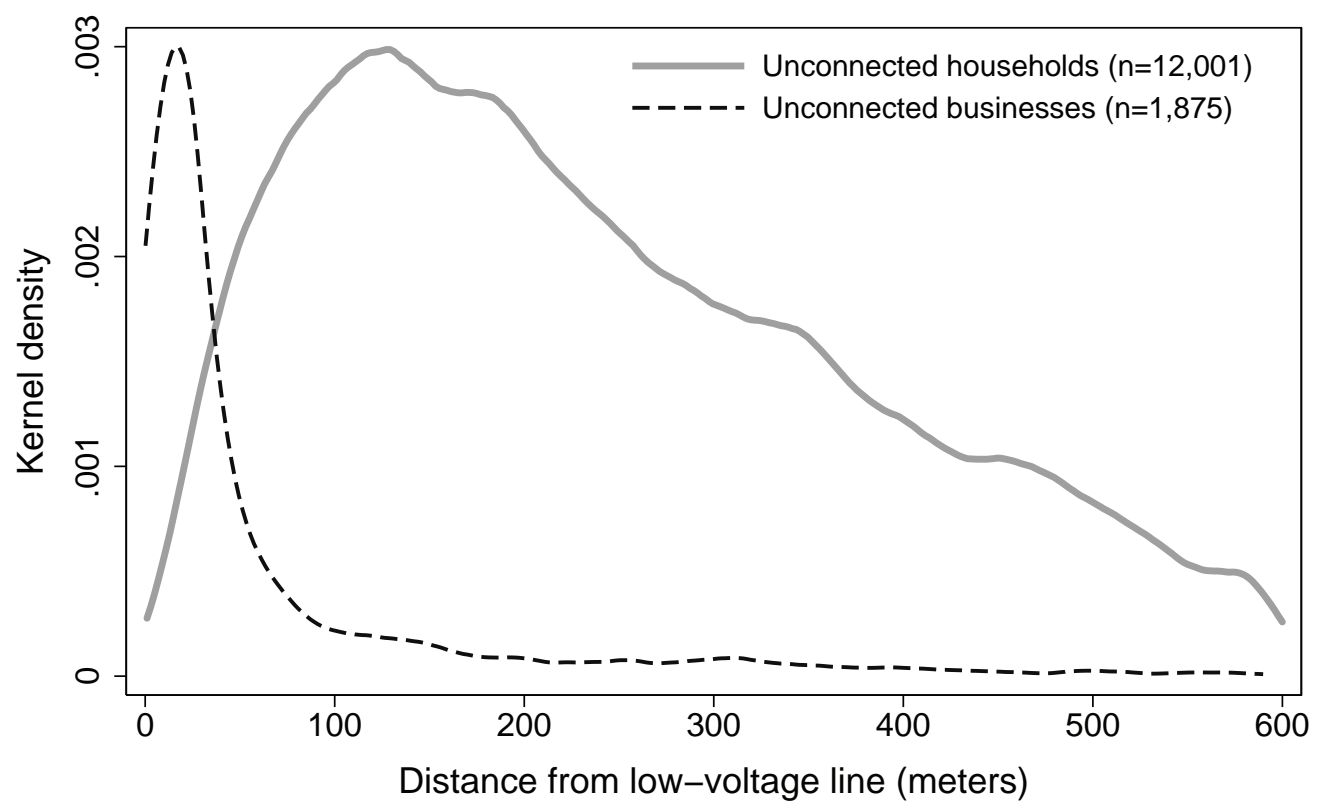

Note: In this figure, we plot Epanechnikov kernels (bandwidth 12). The horizontal axis represents the distance of the unconnected household or business to the nearest connection point or transformer. The vertical axis scale applies to household density only. The peak density for businesses is 0.016 . The figure illustrates that: (1) the mass of unconnected households is within 100 and 200 meters of a low-voltage line, and (2) the mass of unconnected businesses is within 50 meters of a low-voltage line (since businesses tend to be clustered in market centers). 
Figure 5: Economies of scale in the cost of providing household electricity connections.

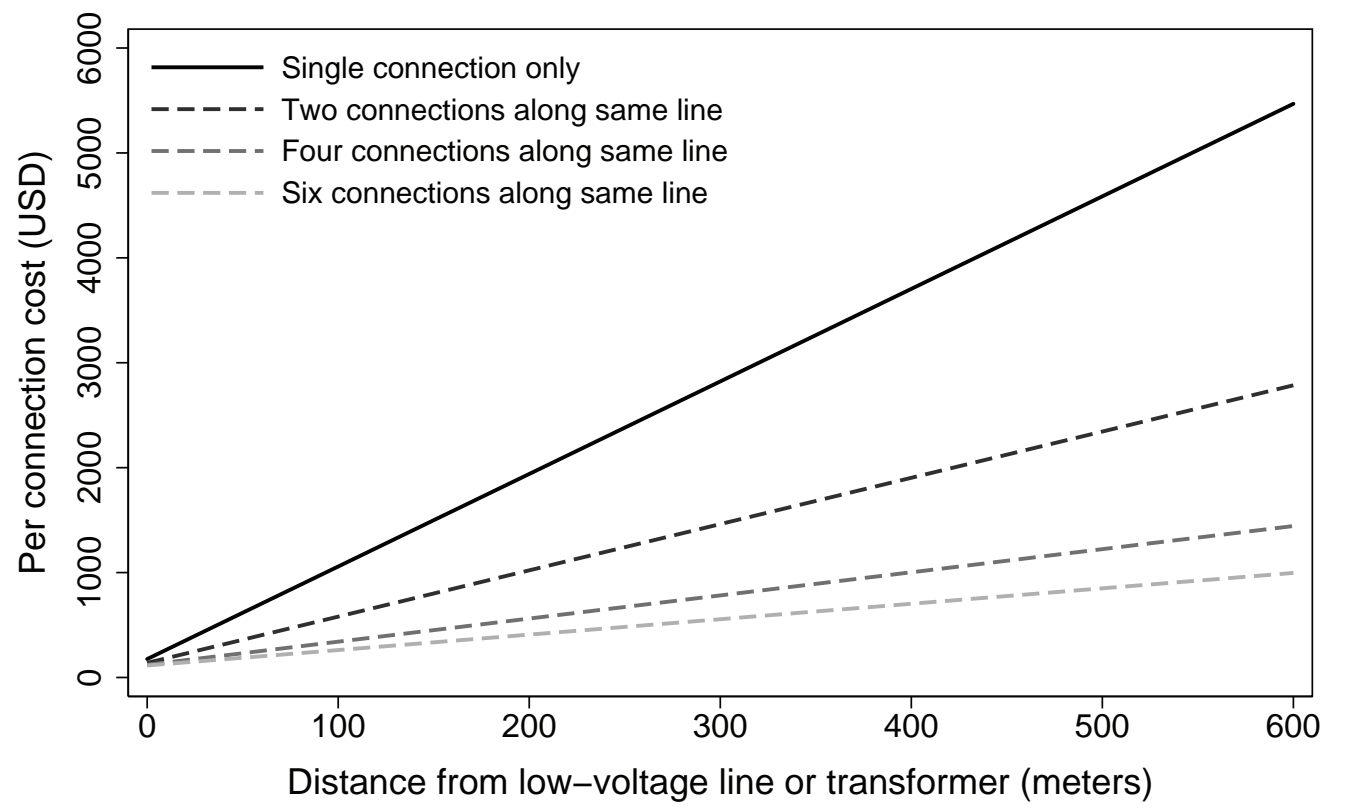

Note: In this figure, we plot the cost of supplying a single-phase connection as a function of distance and the number of neighboring households connecting to the same length of lowvoltage line. These neighboring households can be located as far as 30 meters away from either side of the line. Our estimates are based on actual assumptions used by REA for budgetary purposes. The horizontal axis can be interpreted as either the distance to the nearest low-voltage line or the distance to the central transformer. The figure illustrates that the cost per household drops dramatically when multiple structures are connected simultaneously due to the fact that they can share some of the infrastructure. 
Figure A1: Maps of transformer communities 1 to 6.
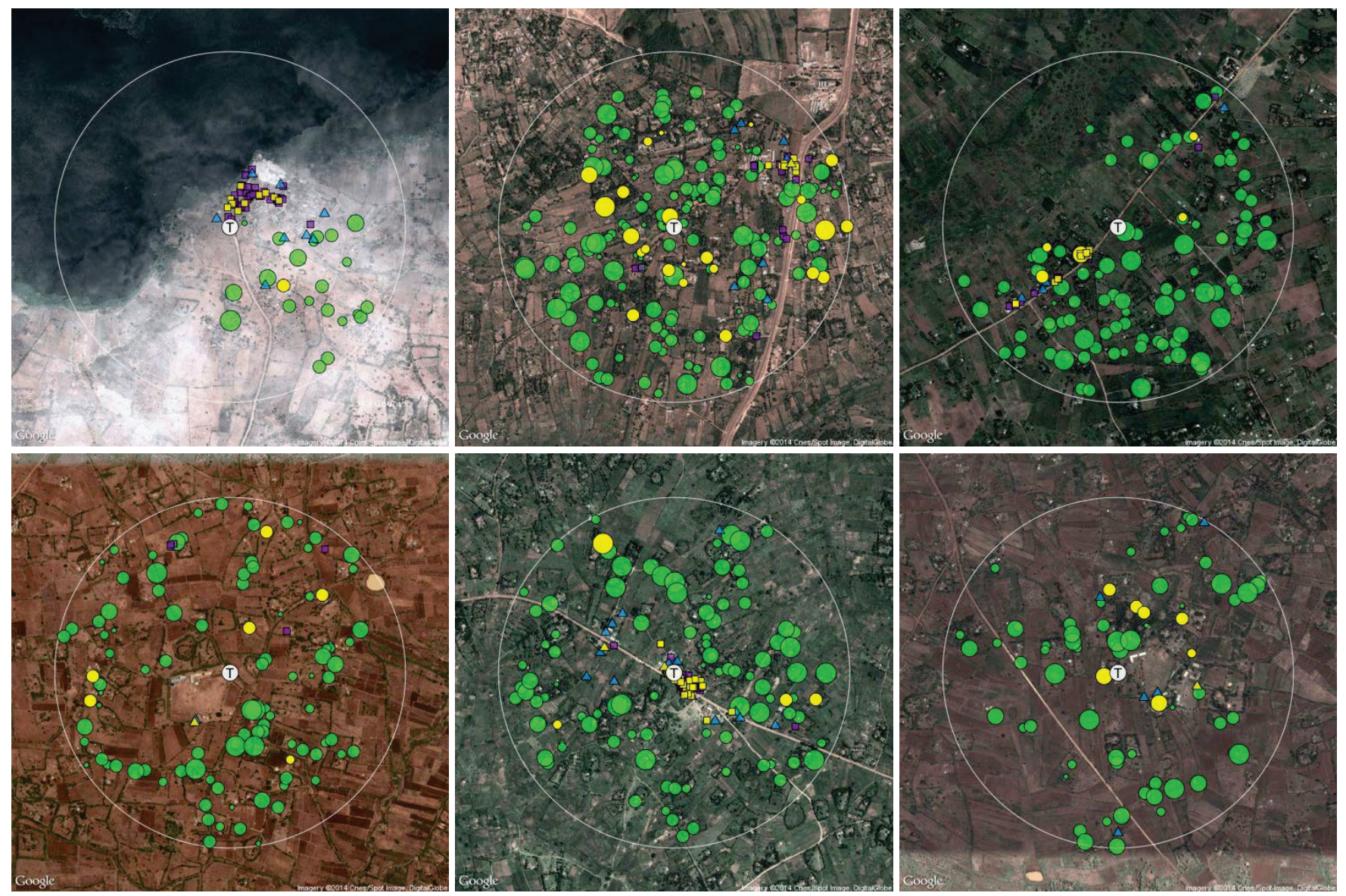

Note: The white circle labeled "T" in the center identifies the location of the REA transformer. The larger white outline demarcates the 600-meter radius boundary. Green circles represent unconnected households; purple squares represent unconnected businesses; and blue triangles represent unconnected public facilities. Yellow circles, squares, and triangles indicate households, businesses, and public facilities with visible electricity connections, respectively. Household markers are scaled by household size, with the largest indicating households with more than ten members, and the smallest indicating single-member households. Residential rental units are categorized as households. 
Figure A2: Maps of transformer communities 7 to 12.
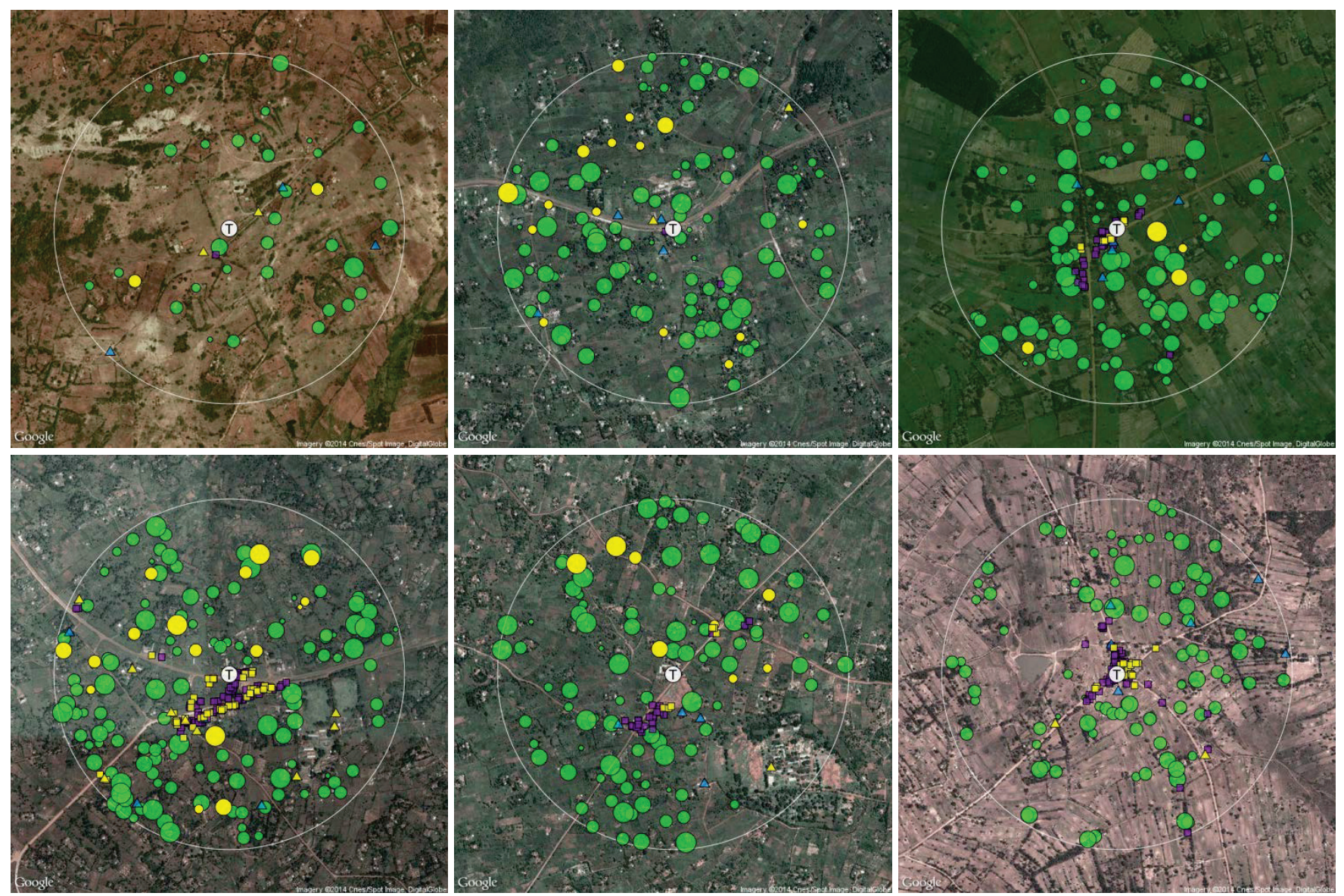

Note: The white circle labeled "T" in the center identifies the location of the REA transformer. The larger white outline demarcates the 600-meter radius boundary. Green circles represent unconnected households; purple squares represent unconnected businesses; and blue triangles represent unconnected public facilities. Yellow circles, squares, and triangles indicate households, businesses, and public facilities with visible electricity connections, respectively. Household markers are scaled by household size, with the largest indicating households with more than ten members, and the smallest indicating single-member households. Residential rental units are categorized as households. 
Figure A3: Maps of transformer communities 13 to 18.
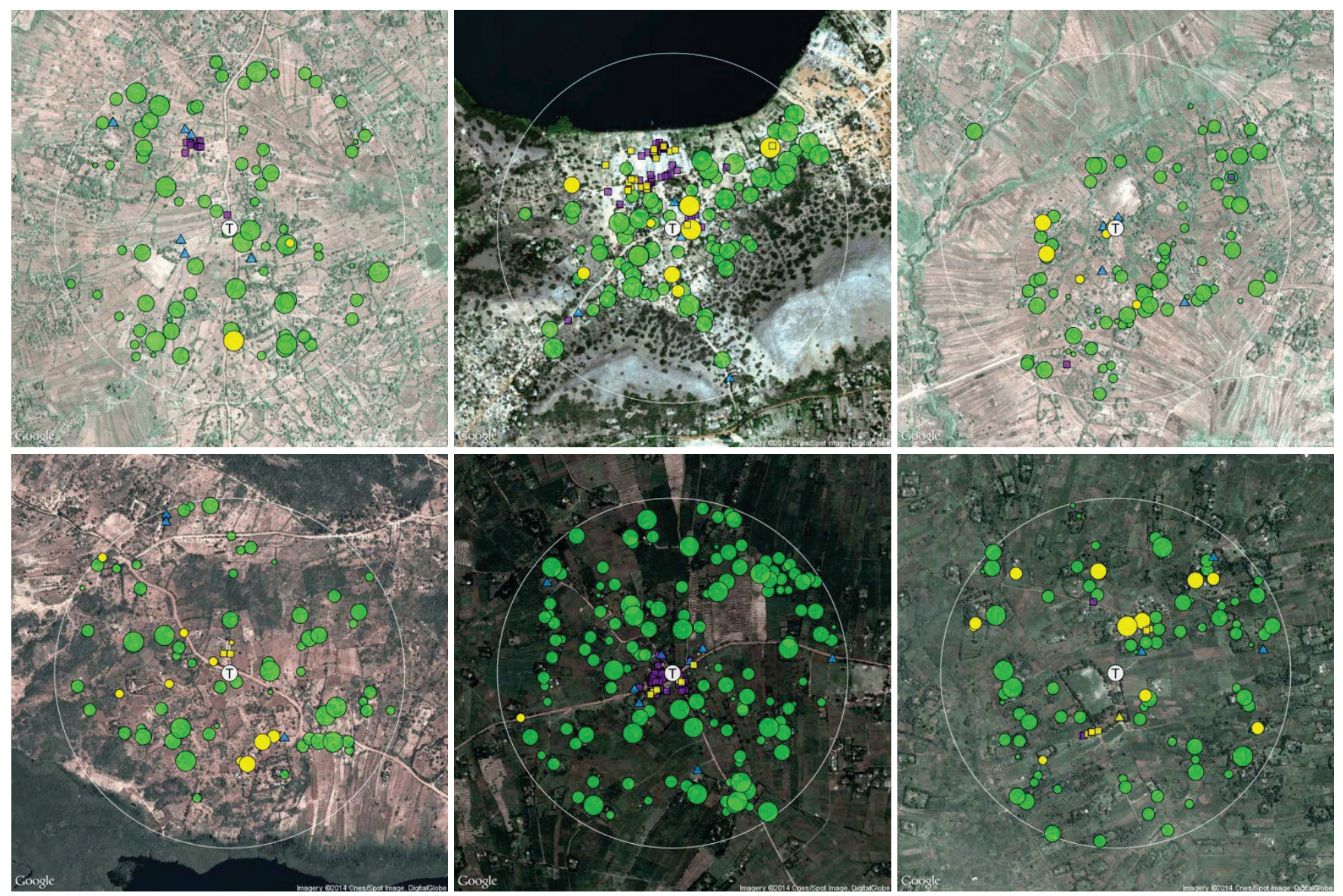

Note: The white circle labeled "T" in the center identifies the location of the REA transformer. The larger white outline demarcates the 600-meter radius boundary. Green circles represent unconnected households; purple squares represent unconnected businesses; and blue triangles represent unconnected public facilities. Yellow circles, squares, and triangles indicate households, businesses, and public facilities with visible electricity connections, respectively. Household markers are scaled by household size, with the largest indicating households with more than ten members, and the smallest indicating single-member households. Residential rental units are categorized as households. 